\title{
Schizotypal personality disorder and MRI abnormalities of temporal lobe gray matter
}

\section{Citation}

Dickey, Chandlee C, Robert W McCarley, Martina M Voglmaier, Margaret A Niznikiewicz, Larry J Seidman, Yoshio Hirayasu, Iris Fischer, et al. 1999. "Schizotypal Personality Disorder and MRI Abnormalities of Temporal Lobe Gray Matter." Biological Psychiatry 45 (11) (June): 1393-1402. doi:10.1016/s0006-3223(99)00030-x.

\section{Published Version}

doi:10.1016/s0006-3223(99)00030-x

\section{Permanent link}

http://nrs.harvard.edu/urn-3:HUL.InstRepos:28501043

\section{Terms of Use}

This article was downloaded from Harvard University's DASH repository, and is made available under the terms and conditions applicable to Other Posted Material, as set forth at http:// nrs.harvard.edu/urn-3:HUL.InstRepos:dash.current.terms-of-use\#LAA

\section{Share Your Story}

The Harvard community has made this article openly available.

Please share how this access benefits you. Submit a story.

\section{Accessibility}




\title{
Schizotypal Personality Disorder and MRI Abnormalities of Temporal Lobe Gray Matter
}

\author{
Chandlee C. Dickey, Robert W. McCarley, Martina M. VogImaier, Margaret A. Niznikiewicz, \\ Larry J. Seidman, Yoshio Hirayasu, Iris Fischer, Eng Kaet Teh, Richard Van Rhoads, \\ Marianna Jakab, Ron Kikinis, Ferenc A. Jolesz, and Martha E. Shenton \\ Department of Psychiatry, Harvard Medical School, Brockton/West Roxbury VAMC, Brockton, \\ Massachusetts; and Department of Radiology, Harvard Medical School, Brigham \& Women's \\ Hospital, Boston, Massachusetts.
}

\begin{abstract}
Background-Structural MRI data indicate schizophrenics have reduced left-sided temporal lobe gray matter volumes, especially in the superior temporal gyrus (STG) and medial temporal lobe. Our data further suggest a specificity to schizophrenia spectrum disorders of STG volume reduction. Interpretation of research studies involving schizophrenics may be complicated by the effects of exposure to neuroleptics and chronic illness. Sharing the same genetic diathesis of schizophrenics, subjects with schizotypal personality disorder (SPD) offer a unique opportunity to evaluate commonalities between schizophrenia and SPD, particularly as SPD subjects are characterized by cognitive and perceptual distortions, an inability to tolerate close friendships, and odd behavior, but they are not psychotic and so have generally not been prescribed neuroleptics nor hospitalized. Evaluation of brain structure in SPD may thus offer insight into the "endophenotype" common to both disorders. In addition, differences between groups may suggest which are the brain structures of schizophrenics that contribute to the development of psychosis.
\end{abstract}

Methods-To test the hypothesis of whether SPD subjects might show similar STG abnormalities, STG and medial temporal lobe regions of interest (ROI) were manually drawn on high resolution coronal MRI $1.5 \mathrm{~mm}$ thick slices. Images were derived from 16 right-handed male SPD subjects, without regard to family history, and 14 healthy, right-handed, comparison males who did not differ from the SPD group on parental socio-economic status, age, or verbal IQ.

Results-As predicted, SPD subjects showed a reduction in left STG gray matter volume compared with age and gender matched comparison subjects. SPD subjects also showed reduced parahippocampal left/right asymmetry and a high degree of disordered thinking. Comparisons with chronic schizophrenics previously studied by us showed the SPD group had a similarity of left STG gray matter volume reduction, but fewer medial temporal lobe abnormalities.

Conclusions-These abnormalities strengthen the hypothesis of a temporal lobe abnormality in SPD, and the similarity of STG findings in schizophrenia and SPD suggest that STG abnormalities may be part of the spectrum "endophenotype." It is also possible that presence of medial temporal lobe abnormalities may help to differentiate who will develop schizophrenia and who will develop the less severe schizophrenia spectrum disorder, SPD.

(C) 1999 Society of Biological Psychiatry

Address reprints to Robert W. McCarley, MD, Brockton VA Medical Center, Psychiatry 116A, 940 Belmont St., Brockton, MA 02401. 


\section{Keywords}

Schizotypal personality disorder; schizophrenia; magnetic resonance imaging; temporal lobe; superior temporal gyrus

\section{Introduction}

A personality disorder is defined in DSM-IV as "an enduring pattern of inner experience and behavior that deviates from the cultural norm and is manifest in cognition, in emotions, in interpersonal functioning, and in impulse control." Recently there has been an increased interest in studying the neurobiology of personality disorders (Cloninger et al 1993; Siever and Davis 1991; Raine 1995), and, in particular, schizotypal personality disorder (SPD). SPD is characterized by cognitive or perceptual distortions, an inability to tolerate close friendships, and odd behavior, but not frank psychosis. Of particular importance to SPD is the concept of the "schizophrenia spectrum," derived from evidence that persons with SPD and schizophrenia often share a common genetic diathesis and show similar, though not identical symptoms (Kety et al 1967). Specifically, Kendler demonstrated that SPD and schizophrenic probands, identified without knowledge of the family history, had approximately the same probability of having a schizophrenic relative, 6.9\% and 6.5\%, respectively (Kendler et al 1993). Research studies of the schizophrenia spectrum disorders have some advantages compared with the study of psychiatric patients. SPD subjects generally have not been prescribed neuroleptics nor have they been chronically ill, both of which can complicate interpretation of research results. Finally, comparison of findings in SPD with those in schizophrenics may help to clarify what are the factors that lead to psychosis.

In addition to the genetic findings, schizophrenics and SPD subjects share other biological abnormalities: (1) behaviorally, they show impaired eye tracking (Siever et al 1990; Siever et al 1994; Clementz et al 1995); (2) neurochemically, they have higher homovanillic acid CSF suggesting dopaminergic dysfunction (Siever et al 1993); (3) neuropsychologically, they demonstrate deficits in attention (Trestman et al 1995), and difficulty clustering semantically similar words, leading to deficits in verbal learning (Voglmaier et al 1997); and (4) electrophysiologically, they show deficits in sensory gating (Perry et al 1997), reduced P3 amplitudes in left vs. right temporal electrodes (Salisbury et al 1996), and longer N400 latency/ increased N400 amplitude to congruent sentences (Niznikiwicz et al submitted).

Despite the recent interest in SPD, the issue of what brain gray matter structural abnormalities, if any, might be present in SPD, remains unresolved. A previous CT study did demonstrate that SPD subjects had larger ventricular brain ratios compared with subjects with other personality disorders (Siever et al 1995) and a MRI study showed ventricular volume in SPD subjects to be intermediate between that of schizophrenic subjects and normal controls (Buchsbaum et al 1997). A second CT study revealed SPD subjects to have sulcal enlargement (Cannon et al 1994). Prefrontal volume reduction has also been associated with a high degree of schizotypy in subjects not diagnosed with SPD (Raine et al 1992).

In contrast, in schizophrenia, many volumetric MRI studies have shown diverse structural abnormalities in many brain regions (for review see Shenton et al 1997; McCarley et al 1999). Studies revealing abnormalities in two regions of the temporal lobe, the gray matter of the superior temporal gyrus (STG) and of medial temporal lobe structures, have been frequently presented (e.g., Schlaepfer et al 1994; Flaum et al 1995; Zipursky et al 1994). For example, anterior STG volume reduction has been correlated with the severity of auditory hallucinations (Barta et al 1990), and, in our laboratory, gray matter reduction in a more posterior portion of the left STG has been correlated with the severity of formal thought disorder (Shenton et al 
1991). These STG abnormalities seem to be specific to schizophrenia, and not to psychosis in general (Pearlson et al 1997; Hirayasu et al 1998). Involvement of the STG is consistent with the finding that SPD subjects have linguistic and verbal learning abnormalities resembling schizophrenia (Voglmaier et al 1997), and language processing is known to involve the STG. In the second region, the medial temporal lobe, volume reductions of the hippocampusamygdala complex and parahippocampal gyrus have been shown in schizophrenia by other investigators (Pearlson et al 1997), as well as by our own laboratory (Shenton et al 1992). Before the current study, however, the temporal lobe of SPD subjects had not been evaluated with thinly sliced, high resolution quantitative volumetric MRI technology.

Where should one look for structural abnormalities in SPD? Our a priori hypothesis was that the SPD subjects would have smaller left STG compared with controls. This was based on the consistency of this finding in our laboratory in both chronic (Shenton et al 1992) and first psychotic episode schizophrenia, and this area's most clear differentiation of first episode schizophrenics from first psychotic episode affective disorder patients, as contrasted with the medial temporal lobe structures of amygdala/hippocampus and parahippocampal gyrus, where the two first episode groups were not significantly different in our data (Hirayasu et al 1998). We also evaluated medial temporal lobe structures for volumetric abnormalities and for departures from normal asymmetry, but did not make specific predictions about findings a priori.

\section{Methods and Materials}

\section{Subject Recruitment}

SPD subjects were recruited from the community as opposed to acquiring SPD patients from clinics. The latter recruitment was not done because it might have opened the sample to bias because of the increased severity and the use of psychotropic medication commonly found in a clinic population. The following newspaper advertisement was, therefore, used to recruit subjects from the general community:

"Sixth Sense/Very Shy: A study at Harvard Medical School seeks right-handed people who believe they have ESP, telepathy, or a "sixth sense;" often mistake noises for voices; sense the presence of others when alone; have extreme social anxiety (or discomfort) in social situations involving unfamiliar people; and have (very) few friends. Earn up to $\$ 200$. Call ..."

This advertisement tapped the DSM-IV diagnostic criteria for SPD that include (symptoms and signs illustrated from our subjects' reports and behavior are in parentheses): (1) ideas of reference (thinking that this study was designed just because the subject needed money); (2) odd beliefs (thinking that concentration could make a cloud change shape) and superstitiousness or "sixth sense;" (3) abnormal perceptual experiences (seeing one's face distort in the mirror, sensing a "presence"); (4) odd and vague speech; (5) paranoia (thinking that co-workers were against one); (6) constricted affect (no change in facial expression); (7) odd and peculiar appearance or behavior; (8) no close friends; and (9) extreme social anxiety (avoiding going to clinic or working with people). At least 5 of these 9 criteria must be met for diagnosis by DSM-IV criteria.

Of the 472 subjects who responded to the advertisement, 303 underwent an extensive telephone screen. The other subjects were female, left handed, or unable to be reached and were thus excluded from further study. Only males were involved in this initial study to eliminate the confounding effect of sex on brain morphology, particularly as limbic structures were evaluated, and sex hormones are known to effect development of limbic structures (McEwen and Magarinos 1997). Future studies will focus on female SPD subjects. During the telephone screen, the subjects were asked questions to see if they fit the inclusion criteria of right-handed 
males between 18 and 55 years old; English as the primary language; no history of neurologic disorder, ECT, drug or alcohol dependence ever or abuse in the last year; and no current use of psychotropic medications (including steroids). In addition subjects were asked each of the diagnostic questions from the SCID II (to assess the presence of personality disorders) for SPD. Of the 303 subjects, 84 met inclusion criteria and answered at least three SCID SPD questions positively. The remaining subjects did not. After complete description of the study to the subjects, written informed consent was obtained. These 84 subjects were given a formal SCID$\mathrm{P}$ and SCID II interview with a licensed psychiatrist or psychologist. The use of a psychiatrist and psychologist was critical as they were trained to probe with follow-up questions and to detect nuances of behavior and history that were needed to establish the correct diagnosis. Interviews were videotaped, and one half were reviewed by a second licensed psychologist to insure proper diagnosis. The interrater reliability for diagnosis of SPD was $\kappa=.89$.

Thirty subjects met at least 5/9 criteria required for the diagnosis of SPD. Of these, nine subjects were lost to follow up, three became claustrophobic in the MRI scanner, and two exceeded the scanner weight limit, leaving a total of 16 SPD subjects. Those SPD subjects from whom MR images were not obtained did not differ from the reported 16 subjects in terms of age, years of education, estimated IQ, personal or parental socio-economic status, or total number of DSMIV criteria met. Only 4 of the 16 SPD subjects had ever had counseling; this consisted of marital, pastoral, or family counseling, with a duration from two weeks to less than one year. None of the subjects had seen a psychiatrist nor been hospitalized for a psychiatric disorder. Subjects were asked about psychiatric treatment and symptoms in relatives. Only one subject gave replies consistent with having a first degree relative with psychosis; two other subjects gave replies consistent with relatives with depression; and one subject reported a relative with autism. Although SPD and schizophrenia share the same genetic diathesis, this study was not a family study. In this subject sample, there does not seem to be obvious heavy genetic loading. SPD subjects had a mean of 1.3 additional DSM-IV personality diagnoses, with the most common being paranoid $(n=6)$ and borderline $(n=5)$ personality disorders. Five SPD subjects also met lifetime criteria for Axis 1 disorders: 2 met for major depression and one each for diagnoses of dysthymia, panic disorder, alcohol abuse and polysubstance abuse (all substance abuse occurred more than 2 years before testing). An additional 5 subjects who met only three to four of the five SPD diagnostic criteria were included in a group termed "sub-threshold." Statistical evaluations of these five subjects should be considered preliminary in nature.

Fourteen SPD subjects were given the Thought Disorder Index (TDI) (Johnston and Holzman 1979); the other two subjects were lost to follow-up before completing the TDI. The TDI consisted of showing subjects 10 Rorschach cards and recording their responses. This language sample was scored for language abnormalities.

Healthy male comparison subjects were recruited from the community with a different advertisement and similarly under-went SCID and SCID II interviews. Comparison subjects had the additional inclusion requirement of no personal or family history of psychotic or bipolar illness nor own personality disorder. Fourteen comparison subjects were age matched to the 16 SPD subjects. The percentage of study completers was not different between the two groups (about 50\%) (see Table 1). Table 1 shows that parental socioeconomic status did not differ between the SPD subjects and comparison subjects, but SPD subjects themselves had a lower socioeconomic status than the comparison group $(t$ value $=-2.39, \mathrm{df}=28, p=.02)$.

\section{MRI procedures}

To allow for comparison, MRI procedures employed were similar to those previously used by this laboratory in a study of schizophrenic patients (Shenton et al 1992). Images were acquired on a 1.5 Tesla MRI system (GE Medical Systems, Milwaukee, WI), the same scanner used for the previous schizophrenia study, although there was an upgrade of the gradient coil and some 
of the software programs used in data analysis. The fact that these hardware and software changes could possibly affect signal intensity was one of the reasons for comparing SPD subjects and schizophrenics on the basis of $\mathrm{z}$ scores. The following acquisition parameters were used: sagittal: localizer series to insure proper prescription of axial and coronal images, (TR $600 \mathrm{~ms}$, TE $19 \mathrm{~ms}, 4.0 \mathrm{~mm}$ thick with $1.0 \mathrm{~mm}$ skip); axial: used in the analysis of intracranial contents (ICC) (52 $3 \mathrm{~mm}$ double-echo spin-echo slices, TR $3000 \mathrm{~ms}$, TE 30 and $80 \mathrm{~ms}, 3.0$ $\mathrm{mm}$ thick and interleaved); and coronal: (124 contiguous slices with no skip, 3D spoiledgradient-recalled-echo, TR $35 \mathrm{~ms}$, TE $5 \mathrm{~ms}$, nutation angle 45 degrees, and voxel size $.975 \times$. $975 \times 1.5 \mathrm{~mm})$. For all images, FOV was $24 \mathrm{~cm}$, with a matrix size of $256 \times 256(192$ phase encoding steps with zero filling). Images were processed on workstations (SPARC2 Sun Microsystem, Mountain View, CA) using locally developed software algorithms. A preprocessing filter was used to remove artifact due to magnetic field inhomogeneity or movement, although maintaining anatomical distinction (Gerig et al 1992).

Temporal lobe gray matter ROIs were drawn without knowledge of diagnosis. The ROIs included the STG, anterior hippocampus/amygdala complex, posterior hippocampus, and the parahippocampus, as illustrated on the coronal section in Figure 1A. The anterior extent of the ROIs was the first slice that contained a clear white matter tract connecting the temporal and frontal lobes; the posterior extent was the slice that contained the complete crux of the fornix. The slice containing the onset of the mamillary bodies was used to divide the hippocampus/ amygdala complex into the posterior hippocampus and the anterior hippocampus/amygdala. The use of the mamillary body as a landmark to separate the structures is arbitrary but highly reliable (Shenton et al 1992; Bogerts et al 1990). As illustrated in Figure 1B, the portion of the STG examined in this study included a small portion of the temporal pole, Heschl's gyrus (unimodal auditory sensory cortex), and the majority of the planum temporale (unimodal auditory association cortex). These boundaries were exactly the same as those used in the previous study of schizophrenics to allow for comparison between studies. The ROI rater employed in this study was trained by the rater of the previous study (M.E.S.), the senior author on the present study. As is standard for our laboratory, and after extensive training, interrater reliability was established for the ROIs by having three different trained raters trace each of the ROIs on scans from three different subjects randomly selected. The intraclass correlations for the interrater reliability for manually drawing the ROIs were high: for the STG, $r=.98$; hippocampus/amygdala complex, $r=.97$; and for the parahippocampus, $r=.95$.

\section{Statistical Methods}

We consistently used non-parametric Mann-Whitney U Tests as ROI volume measurements were not normally distributed. Because our a priori hypothesis was that the SPD subjects would have smaller left STG compared with controls, the $p$ values for that comparison do not reflect correction for multiple comparisons; further, although a one-tailed test would be appropriate for testing this a priori hypothesis, we conservatively use a two-tailed test. For other, nonpredicted comparisons, we adjusted for multiple comparisons. The finding of parahippocampal asymmetry was not predicted and was demonstrated during post hoc analysis, as were all tests of asymmetry. For these non-predicted comparisons, alpha level for statistical significance was set at $p<.004$, calculated as four ROIs times three measures (left, right, and asymmetry).

To correct for potential differences in brain size, the following procedures were performed. Initially, we calculated a simple ratio of absolute ROI volume to ICC, termed the relative volume. Because there remained a correlation between relative volumes and ICC, we performed linear regression measures on the absolute volume to adjust for ICC (see Table 2). Although it is generally agreed upon that it is important to statistically account for the differences of overall brain size, there is no clear standard for accomplishing this. Many laboratories prefer using this linear regression method. We include data for each step to allow 
for comparison with other studies in the literature. Effect size calculations for the asymmetry comparisons used the standard deviation from the control group. $Z$ scores were used to compare schizophrenic and SPD volumes as the two subject groups were not matched and differed on demographic variables that may co-vary with ROI volume such as socioeconomic status (Pearlson et al 1989) and years of education (Andreasen et al 1990), in addition to potential signal intensity issues described above. The means and standard deviations came from each study's respective comparison groups.

\section{Results \\ SPD Volumetric Measures}

As illustrated in Figure 2, the principal finding of this study was that the SPD subjects had a statistically significant gray matter volume reduction of the left STG compared with the comparison group using absolute volumes ( $\mathrm{U}=45, p<.005$, two-tailed); this figure also shows that the absolute volumes of the sub-threshold subjects did not differ from the comparison group. After using a linear regression correction for the volume of total intracranial contents, the STG remained significantly smaller in the SPD sample than in the comparison group (U = $56, p<.02$, two-tailed). In the limited pilot comparison, sub-threshold subjects did not differ from the comparison group on this measure ( $\mathrm{U}=27, p=.46$, two-tailed). We realize these results from such a small sample must be interpreted judiciously, and confirmation in a new sample will be needed to determine whether or not such findings are present in a larger sample of sub-threshold subjects.

No other ROI differed significantly between the SPD and comparison groups, nor was there a difference in ICC between the SPD and comparison groups ( $\mathrm{U}=83, p<.23$, two-tailed). The mean number of slices used in the volume determination did not differ between the SPD and comparison subjects ( $\mathrm{U}=73.0, p=.1$, two-tailed).

Parahippocampal asymmetry, measured as left minus right ICC-adjusted volume, was significantly different in the two groups with SPD subjects showing a more negative left minus right difference than comparison subjects $(\mathrm{U}=40, p<.003$, two-tailed, effect size of 1.03). STG asymmetry was not significant when adjusted for multiple comparisons although SPD subjects had a more negative left minus right difference $(\mathrm{U}=74, p=.11$, two-tailed, effect size of 0.58 ). Sub-thresholds did not differ from comparison subjects on measures of asymmetry.

\section{SPD MRI Comparisons with Schizophrenics}

To compare the present volumes with our previously reported data from 15 right-handed chronic schizophrenic males (with a mean age of 37.6) (Shenton et al 1992), all ICC adjusted volumes were converted to $\mathrm{Z}$ scores (as described in Methods, the $\mathrm{z}$-score conversion was necessary because the SPD and schizophrenic groups were not demographically matched and because of the possible effect of upgrades in imaging hardware and software in the time between scanning the schizophrenic and SPD groups). Figure 3 shows that, as predicted, there was no difference in left STG volume Z scores between the schizophrenics and the SPD subjects $(\mathrm{U}=96, p=.34)$. The $\mathrm{Z}$ scores of schizophrenics, compared with the SPD subjects, did show a smaller anterior hippocampus/amygdala complex on the left $(\mathrm{U}=116, p=.03)$; two other medial temporal lobe structures showed a trend toward statistically significant smaller values for schizophrenic subjects, anterior hippocampus/amygdala complex on the right $(\mathrm{U}=105$, $p=.053)$ and right parahippocampus $(\mathrm{U}=72, p=.058)$.

\section{Thought Disorder}

The SPD subjects demonstrated a marked degree of thought disorder with a mean score of 24.5 $(\mathrm{SD}=19.21)$ on the Thought Disorder Index, approximately half of that of schizophrenics 
(Figure 4). Sub-threshold subjects exhibited less thought disorder (mean =9.0, SD = 4.4) than SPD subjects but more than normal controls who score $<5$ on this measure (Johnston and Holzman 1979). There was no correlation between thought disorder and STG volume, nor with the volume of any other ROI.

\section{Discussion}

This report's main finding of reduced left (dominant hemisphere) gray matter volume of STG in SPD subjects provides the first quantitative volumetric evidence of temporal lobe gray matter change in SPD. Although altered neurotransmitter systems (Cloninger et al 1993; Siever and Davis 1991) and genetics (Kendler 1988; Kendler et al 1993) have been proposed to contribute to the etiology of some personality disorders, abnormal brain structure has generally not been described as a factor (Gunderson and Phillips 1995). The findings of the present high resolution quantitative volumetric MRI study, in conjunction with previous reports (Raine et al 1991; Cannon et al 1994; Siever et al 1995; Buchsbaum et al 1997), offer increasing evidence for brain abnormalities in SPD.

Interestingly, the STG gray matter volume reduction was specific to SPD subjects who met full criteria, as contrasted with its absence in the limited comparison with the sub-threshold subjects, who met only 3-4 of the required 5 SPD DSM-IV diagnostic criteria. If this pilot finding holds as the number of sub-threshold subjects increases, this may support the validity of the DSM-IV criteria for SPD. The comorbid diagnoses in our SPD subject group serve to strengthen our findings as it would not be predicted that a diverse set of diagnoses would have the same anatomic abnormality.

A key point in our study was the ability to follow the same MRI and ROI protocol used previously by our laboratory in the study of schizophrenia (Shenton et al 1992). ROI were similarly hand traced as opposed to automatically segmented—current automated programs have difficulty distinguishing subtle gray/white matter distinctions, particularly in morphometrically complex structures such as the hippocampus, and manual tracing remains the current standard for ROI definition (see consensus report of a recent neuroimaging conference, McCarley et al 1996; and reviews, Shenton et al 1997; McCarley et al 1999). In the original study of chronic schizophrenics by Shenton and colleagues, the schizophrenics compared with their matched control group showed left hemisphere volume reductions in the STG, anterior amygdala/hippocampus complex and parahippocampus (Shenton et al 1992). That was a more extensive set of abnormalities than was found in this current study of SPD subjects, where we have shown the SPD subjects to have left sided abnormalities only in the left STG compared with their matched control group.

These findings support the hypothesis of the importance of STG involvement in the schizophrenia spectrum disorders. A recent review (McCarley et al 1999) has pointed to converging evidence that, especially when STG gray matter volume is measured on high resolution MRI scans, it is reduced in schizophrenics. As described in this review, all 7 of the studies evaluating STG gray matter in schizophrenics compared with comparison subjects showed reduced volumes (Shenton et al 1992; Schlaepfer et al 1994; Zipursky et al 1994; Menon et al 1995; Hajek et al 1997; Sullivan et al 1998; Hirayasu et al 1998), as did six of the nine studies lumping gray and white matter together (Barta et al 1990; Flaum et al 1995; Tune et al 1996; Barta et al 1997; Marsh et al 1997; Reite et al 1997). Negative findings were reported in three studies (Vita et al 1994; Kulynych et al 1996; Woodruff et al 1997). The specificity of volume reduction in the STG segment measured in the present study to schizophrenia spectrum disorders is suggested by the absence of this finding in chronic bipolar disorder subjects (Schlaepfer et al 1994; Pearlson et al 1997) and our own data on first psychotic episode subjects with bipolar disorder (Hirayasu et al 1998). 
Our findings are also consistent with other data pointing to left temporal lobe abnormalities in the schizophrenia spectrum disorders (McCarley et al 1993a), including neuropsychological (Green et al 1994; Nestor et al 1993; Voglmaier et al 1997); evoked potential (McCarley et al 1993b; O'Donnell et al 1993), and neuroimaging data (for review see Shenton et al 1997; Pearlson et al 1997; Bogerts et al 1990; Rossi et al 1993; Petty et al 1995; Turetsky et al 1995).

The abnormal TDI scores in SPD finding is consistent with a recent study that used the TDI with biological relatives of schizophrenic probands who were were adopted away at about one month of age. These relatives were given a semi-structured interview (SADS) not unlike the SCID. Six of the subjects met criteria for either borderline schizophrenia $(n=3)$ or $\operatorname{SPD}(n=$ 3 ) and this combined group of six did exhibit a trend toward an elevated TDI not found in the control adoptees (Kinney et al 1997). Of the three SPD subjects, two had TDI scores greater than the siblings of the control group and one had a TDI score higher than the mean for the schizophrenics (Dr. Kinney, personal communication). In their comments, Kinney et al, suggested that the thought disorder may be due to genetic factors in the schizophrenia spectrum (Kinney et al 1997). As the STG is thought to be an important substrate for language processing, the finding of abnormal STG morphology SPD is consonant with the clinical symptomatology of language abnormalities (see review McCarley et al 1993a). Unlike the chronic schizophrenic sample (Shenton et al 1992) there was no direct correlation between the TDI scores and the left STG gray matter volume, nor with the volume of any other ROI in these SPD subjects. This may reflect, in SPD subjects, a more subtle relationship between clinical variables and any one structural ROI than in the schizophrenic sample, or a relationship between TDI and one or more of the ROI we did not examine.

An important general question in studies of the schizophrenia spectrum is why are schizophrenics psychotic, although SPD subjects are not, given their similar genetic diathesis. This paper has shown that SPD subjects have left STG volume reduction and parahippocampal asymmetry although schizophrenics have more extensive abnormalities, especially in the medial temporal lobe (Shenton et al 1992). In the absence of a specific gene found for schizophrenia, it is not possible to determine causation, but it is conceivable that the additional structural abnormalities in schizophrenia may account, in part, for the difference in clinical severity. The features of SPD may be due to a series of cognitive and language/thought processing abnormalities occurring along a circuit in the temporal lobe. We have demonstrated reduced gray matter volume of the left STG, an important area of language processing. Information from the STG passes to the parahippocampal complex. What forms of information processing might occur in the parahippocampus is less well known, but this structure is the key input/output zone for the hippocampus (Squire and Zola-Morgan 1991). Recently, direct electrical recordings from the anterior medial temporal lobe (including the hippocampus/ parahippocampus) have implicated this area in the processing of semantic representations (McCarthy et al 1995) as well as being important for memory retrieval. Schizophrenics have volume reductions in both in the STG and medial temporal portions of this circuit although SPD subjects have only STG volume reductions. This difference might account, in part, for the additional clinical symptoms in schizophrenia such as overt auditory hallucinations and paranoid ideation. For example, recent neuroimaging studies of schizophrenics have shown abnormal hippocampal activation during hallucinations (Silbersweig et al 1995). Whether additional structural abnormalities exist in other brain regions in SPD and whether females with SPD are similarly effected remains to be further elucidated.

Another important question concerns the potential mechanisms leading to greater structural alterations in schizophrenia. One mechanism might be gene interactions during brain development that occur in schizophrenia but not SPD, although another, non-exclusive possibility is post-natal medial temporal lobe volume reduction in schizophrenia (McCarley et 
al 1996). Data presented here suggest that the singular volume reduction of the STG might be regarded as a potential biological marker of the schizophrenia spectrum, a component of the "endophenotype." The possible role of environmental factors in triggering a full-blown schizophrenic episode suggests also that the STG volume reduction might be a vulnerability marker. If patients can be differentiated into those who will have a more benign course and those who will have a more serious illness, early in their presentation, then research might be directed toward early intervention either with different social, cognitive, or pharmacologic treatments that may allow better compensation for the anatomic abnormalities.

\section{Acknowledgments}

This work was supported by NARSAD; Dupont Warren and VA Psychiatry/Neuroscience Research Fellowship Award; NIMH MH 52807; Dept. Veterans Affairs Center for Clinical and Basic Neuroscience Studies of Schizophrenia; NIH P41 RR13218; NIMH KO2-MH-01110 and NIMH R29 MH 50740.

\section{References}

Andreasen N, Ehrhardt J, Swayze VI, Alliger R, Yuh W, Cohen G, et al. Magnetic resonance imaging of the brain in schizophrenia. Arch Gen Psychiatry 1990;47:35-44. [PubMed: 2294854]

Barta PE, Pearlson GD, Powers RE, Richards SS, Tune LE. Auditory hallucinations and smaller superior temporal gyral volume in schizophrenia. Am J Psychiatry 1990;147:1457-1462. [PubMed: 2221156]

Barta PE, Powers RE, Aylward EH, Chase GA, Harris GJ, Rabins PV, et al. Quantitative MRI volume changes in late onset schizophrenia and Alzheimer's disease compared to normal controls. Psychiatry Res 1997;68:65-75. [PubMed: 9104754]

Bogerts B, Ashtari M, Degreef G, Alvir JMJ, Bilder RM, Lieberman JA. Reduced temporal limbic structure volumes on magnetic resonance images in first episode schizophrenia. Psychiatry Res Neuroimaging 1990;35:1-13.

Buchsbaum MS, Yang S, Hazlett E, Siegal BV, Germans M, Haznedar M, et al. Ventricular volume and asymmetry in schizotypal personality disorder and schizophrenia assessed with magnetic resonance imaging. Schiz Res 1997;27:45-53.

Cannon TD, Mednick SA, Parnes J, Schulsinger F, Praestholm J, Vestergaard A. Developmental brain abnormalities in the offspring of schizophrenic mothers II: Structural brain characteristics of schizophrenia and schizotypal personality disorder. Arch Gen Psychiatry 1994;51:955-962. [PubMed: 7979884]

Clementz BA, Reid SA, McDowell JE, Cadenhead KS. Abnormality of smooth pursuit eye movement initiation: specificity to the schizophrenia spectrum? Psychophysiology 1995;32:130-134. [PubMed: 7630977]

Cloninger R, Svrakic D, Przybeck T. A psychobiological model of temperament and character. Arch Gen Psychiatry 1993;50:975-990. [PubMed: 8250684]

DeLisi L, Hoff A, Neale C, Kushner M. Asymmetries in the superior temporal lobe in male and female first-episode schizophrenic patients: measures of planum temporale and superior temporal gryus by MRI. Schizophr Res 1993;12:19-28. [PubMed: 8018582]

Flaum M, Swayze V, O'Leary D, Yuh W, Ehrhardt J, Arndt S, et al. Effects of diagnosis, laterality, and gender on brain morphology in schizophrenia. Am J Psychiatry 1995;152:704-714. [PubMed: 7726310]

Gerig G, Kubler O, Kikinis R, Jolesz F. Non-linear aniosotropic filtering of MRI data. IEEE Trans Med Imaging 1992;11:221-232. [PubMed: 18218376]

Green MF, Hugdahl K, Mitchell S. Dichotic listening during auditory hallucinations in patients with schizophrenia. Am J Psychiatry 1994;151:357-362. [PubMed: 8109643]

Gunderson, J.; Phillips, K. Personality disorders. In: Kaplan, H.; Sadock, B., editors. Comprehensive Textbook of Psychiatry. 6th ed.. Baltimore: Williams \& Wilkins; 1995. p. 1425-1461.

Hajek M, Huonker R, Boehle C, Volz HP, Nowak H, Sauer H. Abnormalities of auditory evoked magnetic fields and structural changes in the left hemisphere of male schizophrenics-a 
magnetoencephalographic-magnetic resonance imaging study. Biol Psychiatry 1997;42:609-616. [PubMed: 9376457]

Hirayasu Y, Shenton ME, Salisbury D, Fischer I, Dickey CC, Arakaki H, et al. MRI and evoked related potentials in first episode schizophrenia and affective psychosis. Schiz Bull 1997;24:148.

Hirayasu Y, Shenton ME, Salisbury DF, Dickey CD, Fischer IF, Mazzoni P, et al. First episode schizophrenics differ from first episode affective psychotics and controls in left temporal lobe MRI volume reductions. Am J Psychiatry 1998;155:1384-1391. [PubMed: 9766770]

Johnston, M.; Holzman, P. Assessing Schizophrenic Thinking: A Clinical and Research Instrument for Measuring Thought Disorder. San Francisco: Jossey-Bass; 1979.

Kendler KS. Familial aggregation of schizophrenia and schizophrenia spectrum disorders. Evaluation of conflicting results. Arch Gen Psychiatry 1988;45:377-383. [PubMed: 3281628]

Kendler KS, McGuire M, Gruenberg AM, O’Hare A, Spellman M, Walsh D. The Roscommon family study I. Methods, diagnosis of probands, and risk of schizophrenia in relatives. Arch Gen Psychiatry 1993;50:527-540. [PubMed: 8317947]

Kety, SS.; Rosenthal, D.; Wender, PH.; Schulsinger, F. The types of prevalence of mental illness in the biological and adoptive families of adoptive schizophrenics. In: Rosenthal, D.; Ketty, SS., editors. Second Research Conference of the Foundation's Fund for Research in Psychiatry. Dorado, Puerto Rico: Pergamon Press; 1967. p. 345-362.

Kinney DK, Holzman PS, Jacobsen B, Jannson L, Faber B, Hildebrand W, et al. Thought disorder in schizophrenic and control adoptees and their relatives. Arch Gen Psychiatry 1997;54:475-479. [PubMed: 9152101]

Kulynych J, Vladar K, Jones D, Weinberger D. Superior temporal gyrus volume in schizophrenia: a study using MRI morphometry assisted by surface rendering. Am J Psychiatry 1996;153:50-56. [PubMed: 8540591]

Marsh L, Harris D, Lim KO, Beal M, Hoff AL, Minn K, et al. Structural magnetic resonance imaging abnormalities in men with severe chronic schizophrenia and an early age at clinical onset. Arch Gen Psychiatry 1997;54:1104-1112. [PubMed: 9400346]

McCarley RW, Shenton ME, O'Donnell B, Nestor P. Uniting Kraeplin and Bleuler: the psychology of schizophrenia and the biology of temporal lobe abnormalities. Harvard Rev Psychiatry 1993a;1:3656.

McCarley RW, Shenton ME, O’Donnell B, Faux S, Kikinis R, Nestor P, et al. Auditory P300 abnormalities and left posterior superior temporal gyrus volume reduction in schizophrenia. Arch Gen Psychiatry 1993b;50:190-197. [PubMed: 8439239]

McCarley RW, Hsiao J, Freedman R, Pfefferbaum A, Donchin E. Neuroimaging and the cognitive neuroscience of schizophrenia. Schiz Bull 1996;22:703-726.

McCarley RW, Wible CG, Frumin M, Hirayasu Y, Levitt J, Fischer IA, et al. MRI anatomy of schizophrenia. Bio Psychiatry 1999;45:1099-1119. [PubMed: 10331102]

McCarthy G, Nobre A, Bentin S, Spencer D. Language-related field potentials in the anterior-medial temporal lobe: 1. Intracranial distribution and neural generators. J Neurosci 1995;15:1080-1089. [PubMed: 7869084]

McEwen BS, Magarinos AM. Stress effects on morphology and function of hippocampus. Ann NY Acad Sci 1997;821:271-284. [PubMed: 9238211]

Menon RR, Barta PE, Aylward EH, Richards SS, Vaughn DD, Tien AY, et al. Posterior superior temporal gyrus in schizophrenia: grey matter changes and clinical correlates. Schizophr Res 1995;16:127-135. [PubMed: 7577766]

Nestor P, Shenton M, McCarley R, Haimson J, Smith R, O’Donnell B, et al. Neuropsychological correlates of MRI temporal lobe abnormalities in schizophrenia. Am J Psychiatry 1993;150:18491855. [PubMed: 8238641]

Niznikiwicz MA, Voglmaler M, Shenton ME, Seidman LJ, Dickey CC, Rhoads R, et al. N400 as an index of language processing in schizotypal personality disorder. Am J Psychiatry. 1999 submitted.

O'Donnell B, Shenton M, McCarley R, Faux S, Smith R, Salisbury D, et al. The auditory N2 component in schizophrenia: relationship to MRI temporal lobe gray matter and to other ERP abnormalities. Biol Psychiatry 1993;34:26-40. [PubMed: 8373937] 
Pearlson G, Kim W, Kubos K, Moberg P, Jayaram G, Bascom M, et al. Ventricular-brain ratio, computed tomography density, and brain area in 50 schizophrenics. Arch Gen Psychiatry 1989;46:690-697. [PubMed: 2751403]

Pearlson G, Barta P, Powers R, Menon R, Richards S, Aylward E, et al. Medial and superior temporal gyral volumes and cerebral asymmetry in schizophrenia versus bipolar disorder. Biol Pscyhiatry 1997;41:1-14.

Perry, W.; Geyer, M.; Cadenhead, K.; Swerdlow, N.; Braff, D. Schizophrenic patients with normal prepulse inhibition?. In: Nasrallah, H.; Delisi, L., editors. The VIth International Congress on Schizophrenia Research. Colorado Springs, Colorado: Elsevier; 1997. p. 231

Petty R, Barta P, Pearlson G, McGilchrist I, Lewis R, Tien A, et al. Reversal of asymmetry of the planum temporale in schizophrenia. Am J Psychiatry 1995;152:715-721. [PubMed: 7726311]

Raine, A. Schizotypal Personality. Raine, A.; Lencz, T.; Mednick, S., editors. New York: Cambridge University Press; 1995.

Raine A, Sheard C, Reynolds GP, Lencz T. Pre-frontal structural and functional deficits associated with individual differences in schizotypal personality. Schizophr Res 1991;7:237-247. [PubMed: 1390403]

Reite M, Sheeder J, Teale P, Adams M, Richardon D, Simon J, et al. Magnetic source imaging evidence of gender differences in cerebral lateralization in schizophrenia. Arch Gen Psychiatry 1997;54:433440. [PubMed: 9152097]

Rossi A, Serio A, Stratta P, Petruzzi C, Schiazza G, Mancini F, et al. Planum temporale asymmetry and thought disorder in schizophrenia. Schiz Res 1993;12:1-7.

Salisbury D, Voglmaier M, Seidman L, McCarley R. Topographic abnormalities of P3 in schizotypal personality disorder. Biol Psychiatry 1996;40:165-172. [PubMed: 8830949]

Schlaepfer T, Harris G, Tien A, Peng L, Lee S, Federman E, et al. Decreased regional cortical gray matter volume in schizophrenia. Am J Psychiatry 1994;151:842-848. [PubMed: 8184992]

Shenton ME, Kikinis R, Jolesz FA, Pollack SD, LeMay M, Wible CG, et al. Abnormalities of the left temporal lobe and thought disorder in schizophrenia: a quantitative magnetic resonance imaging study. NEJM 1992;327:604-612. [PubMed: 1640954]

Shenton, ME.; Wible, CG.; McCarley, RW. A review of magnetic resonance imaging studies of brain abnormalities in schizophrenia. In: Krishnan, KRR.; Doraiswamy, PM., editors. Brain Imaging in Clinical Psychiatry. New York: Marcel Dekker; 1997. p. 297-380.

Siever LJ, Keefe R, Bernstein DP, Coccaro EF, Klar HM, Zemishlany Z, et al. Eye tracking impairment in clinically identified patients with schizotypal personality disorder [see comments]. Am J Psychiatry 1990;147:740-745. [PubMed: 2343917]

Siever LJ, Davis K. A psychobiological persepective on the personality disorders. Am J Psychiatry 1991;50:975-990.

Siever LJ, Ammin F, Coccaro EF, Trestman R, Silverman J, Horvath TB, et al. CSF homovanillic acid in schizotypal personality disorder. Am J Psychiatry 1993;150:149-151. [PubMed: 8417559]

Siever LJ, Friedman L, Moskowitz J, Mitropoulou V, Keefe R, Roitman SL, et al. Eye movement impairment and schizotypal psychopathology. Am J Psychiatry 1994;151:1209-1215. [PubMed: 8037257]

Siever LJ, Rotter M, Losonczy M, Guo S, Mitropoulou V, Trestman R, et al. Lateral ventricular enlargement in schizotypal personality disorder. Psychiatry Res 1995;57:109-118. [PubMed: 7480378]

Silbersweig D, Stern E, Frith C, Cahill C, Holmes A, Grootoonk S, et al. A functional neuroanatomy of hallucinations in schizophrenia. Nature 1995;378:176-179. [PubMed: 7477318]

Squire L, Zola-Morgan S. The medial temporal lobe memory system. Science 1991;253:1380-1386. [PubMed: 1896849]

Sullivan EV, Mathalon DH, Lim KO, Marsh L, Pfefferbaum A. Patterns of regional cortical dysmorphology distinguishing schizophrenia and chronic alcoholism. Biol Psychiatry 1998;43:118131. [PubMed: 9474444]

Trestman RL, Keefe RS, Mitropoulou V, Harvey PD, de Vegvar ML, Lees-Roitman S, et al. Cognitive function and biological correlates of cognitive performance in schizotypal personality disorder. Psychiatry Res 1995;59:127-136. [PubMed: 8771227] 
Tune L, Barta P, Wong D, Powers RE, Pearlson G, Tien AY, Wangner HN. Straital dopamine $\mathrm{D}_{2}$ receptor quantification and superior temporal gyrus: volume determination in 14 chronic schizophrenic subjects. Psychiatry Res 1996;67:155-158. [PubMed: 8876015]

Turetsky B, Cowell P, Gur R, Grossman R, Shtasel D, Gur R. Frontal and temporal lobe brain volumes in schizophrenia. Arch Gen Psychiatry 1995;52:1061-1070. [PubMed: 7492258]

Vita A, Dieci M, Giobbio GM, Garbarini M, Morganti C, Braga M, et al. A reconsideration of the relationship between cerebral structural abnormalities and family history of schizophrenia. Psychiatry Res 1994;53:41-55. [PubMed: 7991731]

Voglmaier M, Seidman L, Salisbury D, McCarley R. Neuropsychological dysfunction in schizotypal personality disorder: a profile analysis. Biol Psychiatry 1997;41:530-540. [PubMed: 9046985]

Woodruff PW, Wright IC, Shuriquie N, Russouw H, Rushe T, Howard RJ, et al. Structural brain abnormalities in male schizophrenics reflect fronto-temporal dissociation. Psych Med 1997;27:12571266.

Zipursky R, Marsh L, Lim K, DeMent S, Shear P, Sullivan E, et al. Volumetric MRI assessment of temporal lobe structures in schizophrenia. Biol Psychiatry 1994;35:501-516. [PubMed: 8038294] 


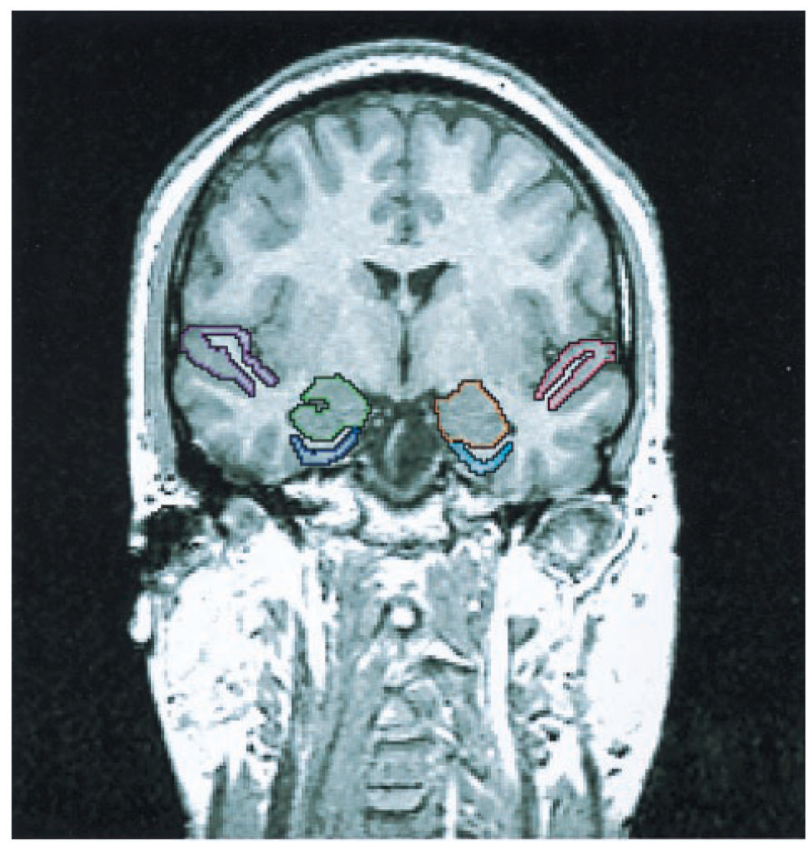

A

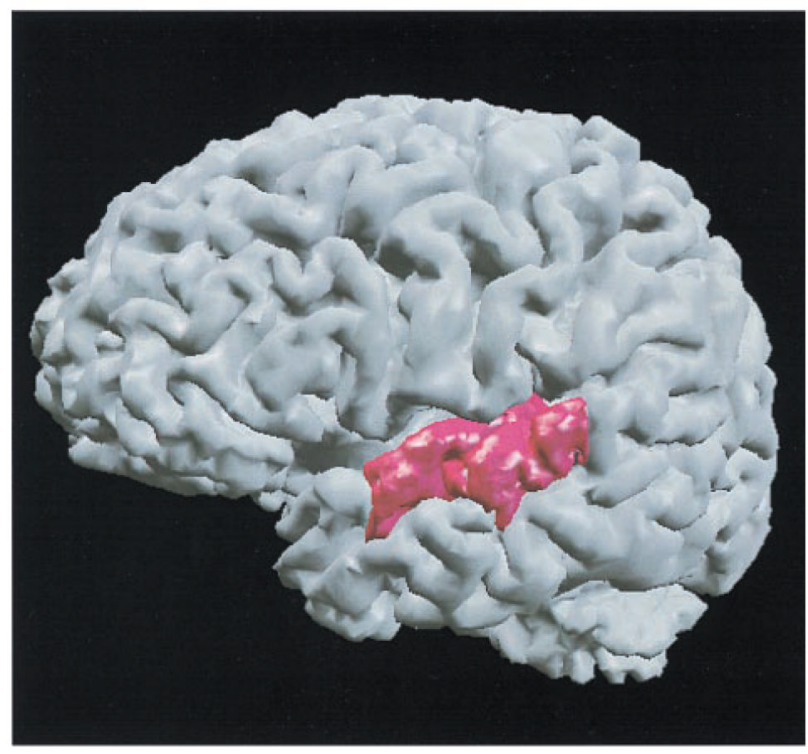

B

Figure 1.

(A) SPGR coronal image demonstrating the manual delineation of the ROI in a SPD subject. Image right side is the left side of the brain. The left STG is shown in red, the right in magenta, left hippocampus is in orange, the right in green, the left parahippocampal gyrus is in bright blue, and the right in purple. (B) MRI 3D rendering of a SPD subject's brain with the left STG highlighted in red. For clearer visualization of the gyral structure, the brain surface was eroded one voxel in constructing this figure. 


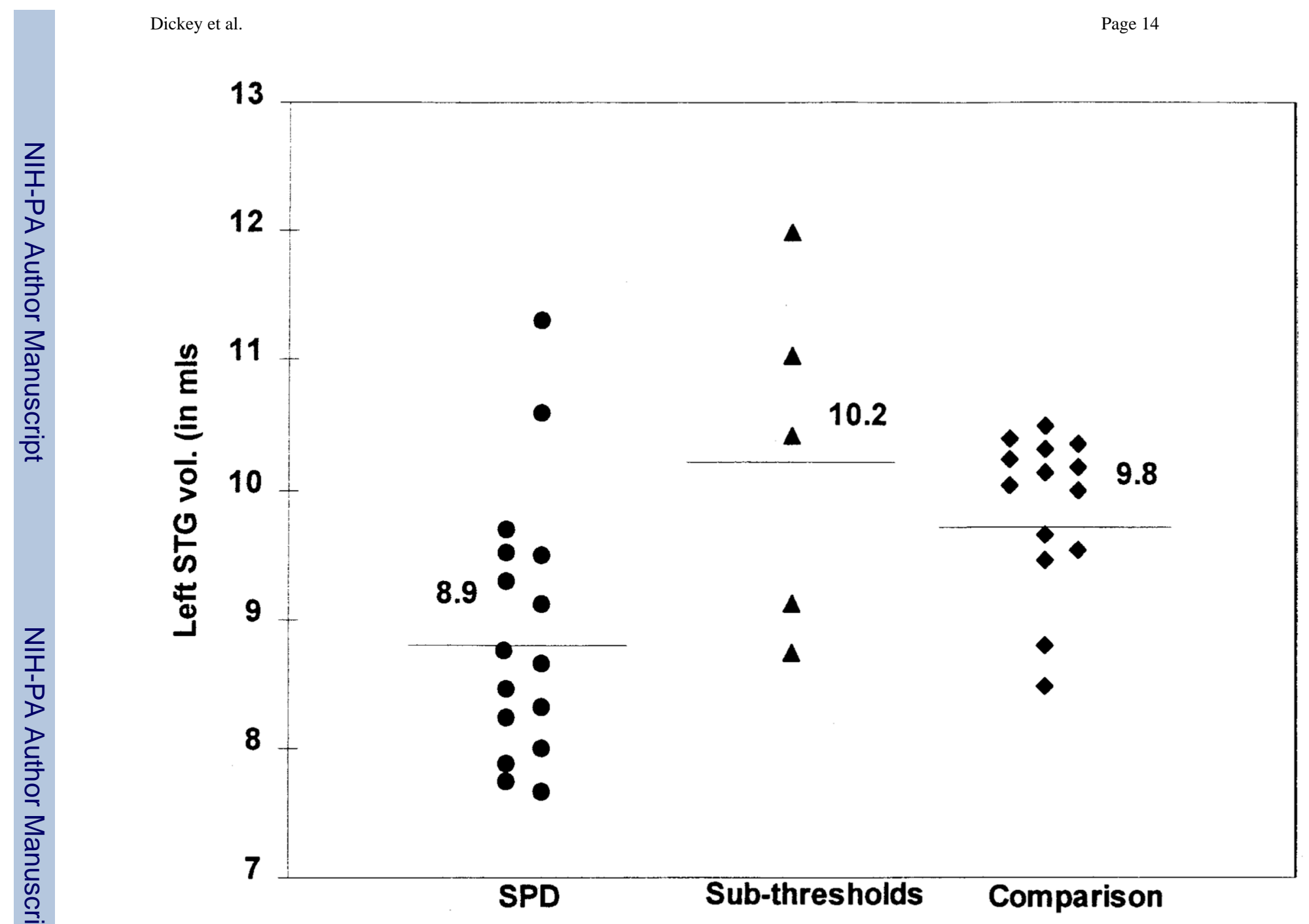

Figure 2.

Left STG absolute gray matter volumes of each subject. Only 2/14 of healthy comparison subjects have left STG volumes less than the SPD mean. Horizontal lines and values indicate group means. 


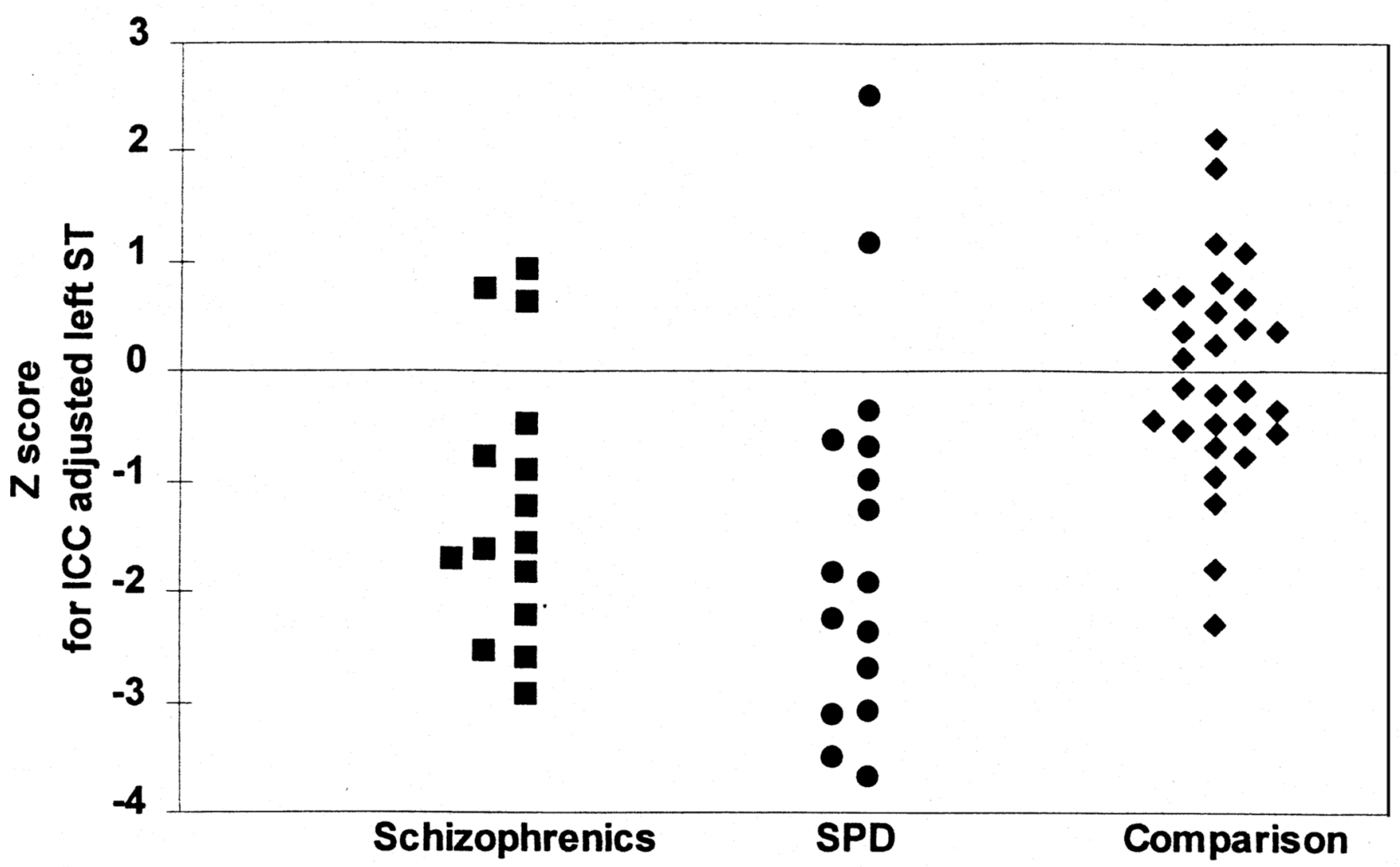

Figure 3.

Z score graph $(\mathrm{SD}=1)$ comparing the ICC adjusted STG gray matter volume for subjects in the schizophrenic (Shenton et al 1992) $(n=15)$, SPD $(n=16)$, and combined comparison (control) group from both the schizophrenic and SPD studies $(n=29)$. 


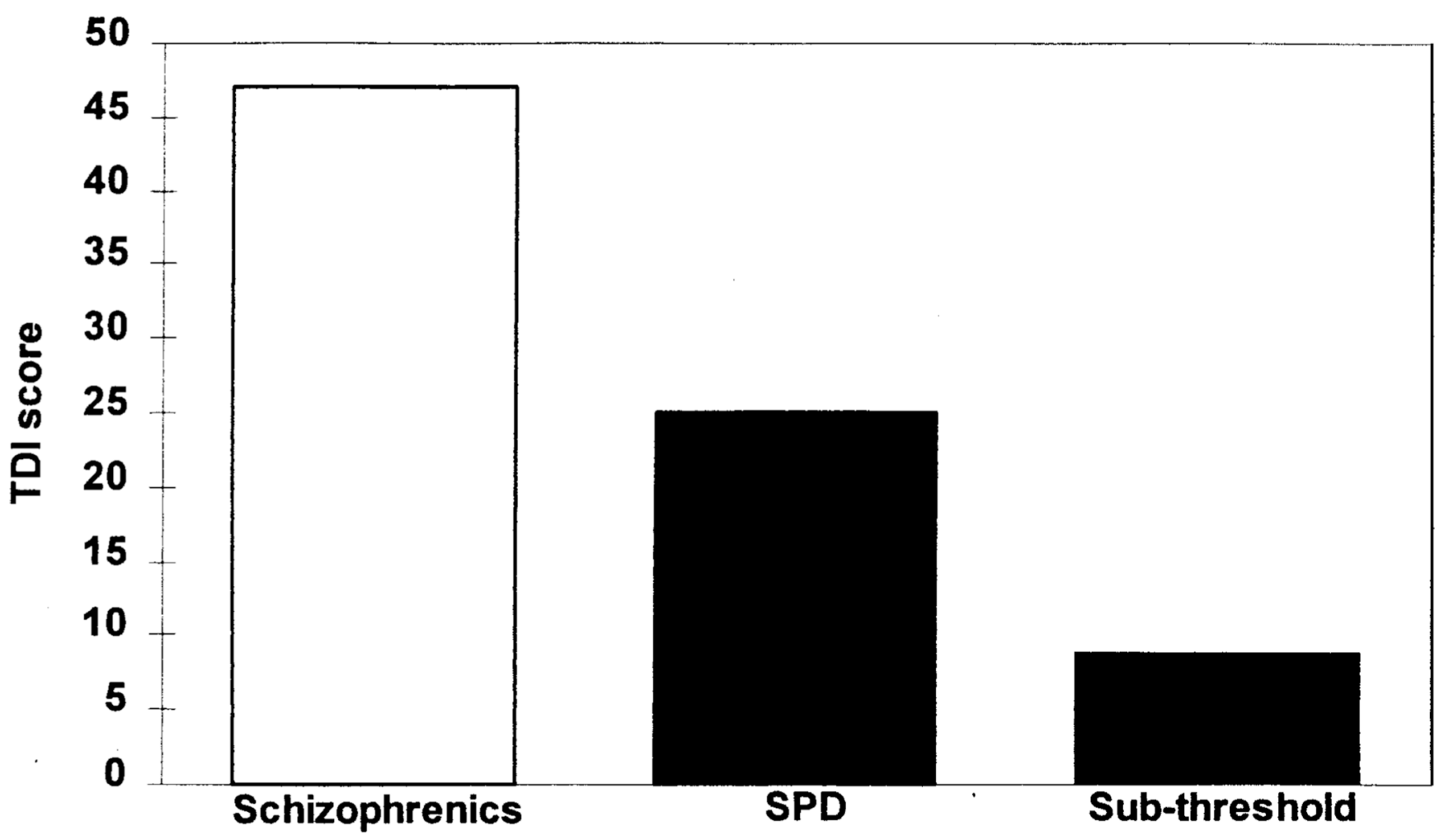

Figure 4.

Graph displaying the degree of formal thought disorder using the Thought Disorder Index for schizophrenic (Shenton et al 1992), SPD, and sub-threshold subjects. 


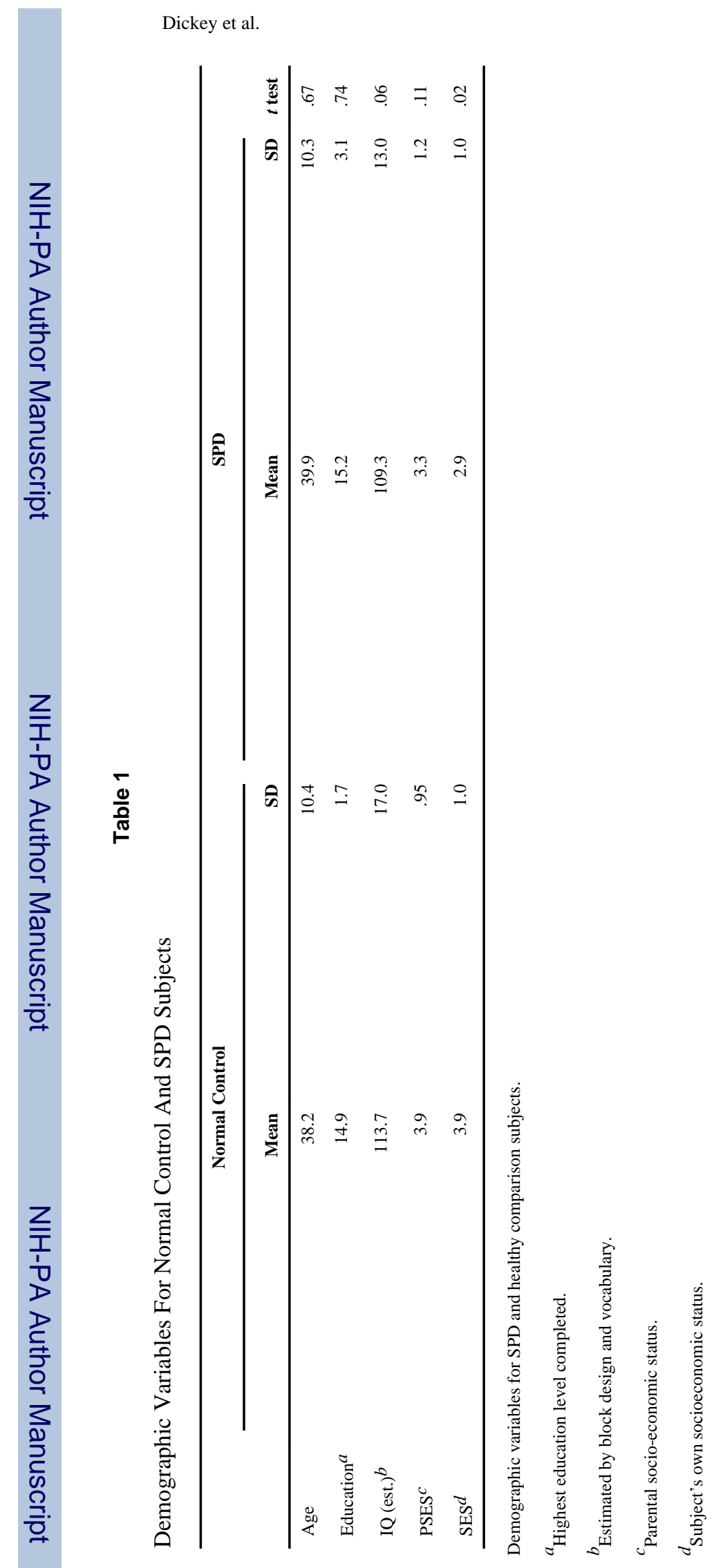

Biol Psychiatry. Author manuscript; available in PMC 2010 March 5. 


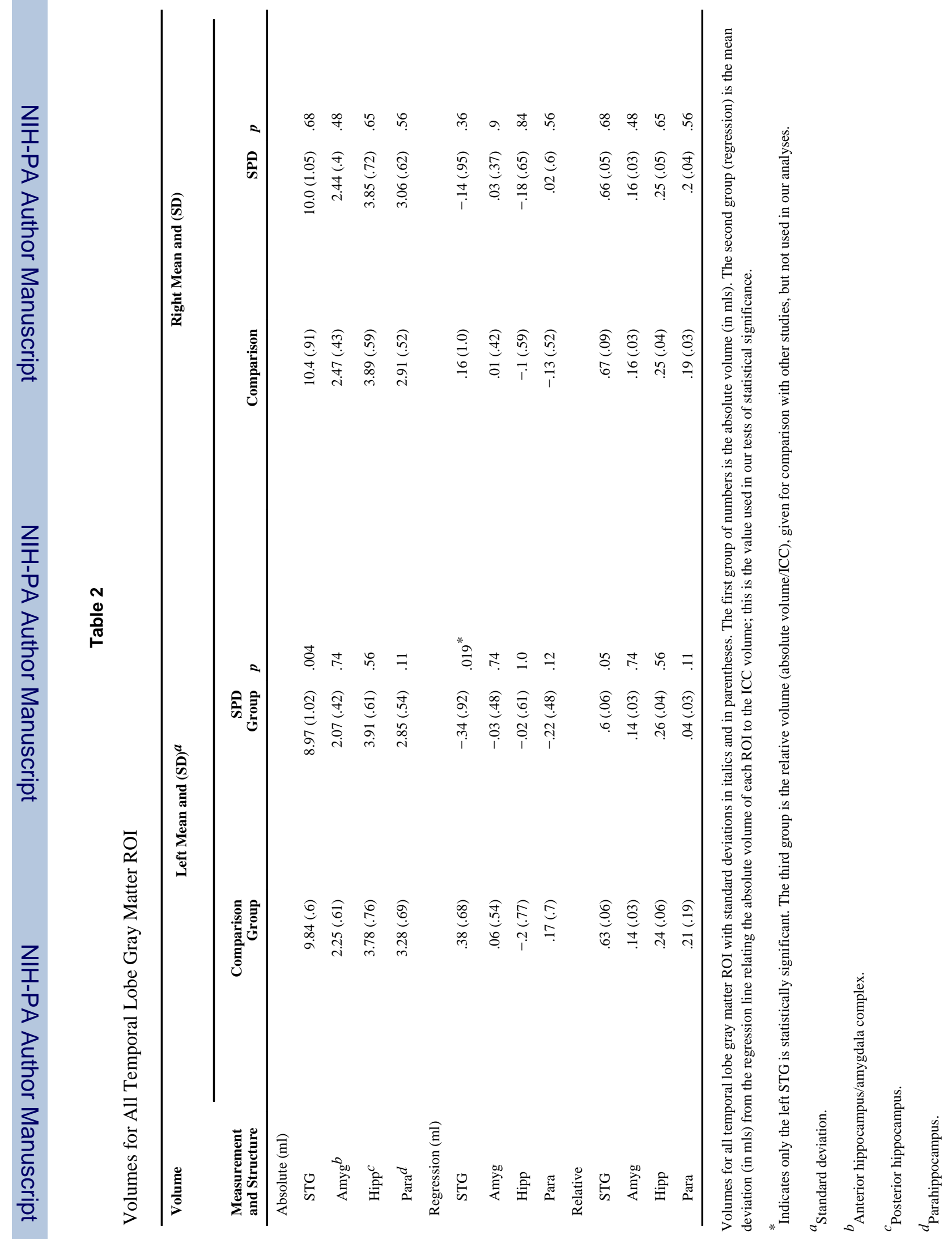

